\title{
Experiência e identidades em (re)construção
}

\author{
Experiencia e identidades en (re)construcción
}

Experience and identities in (re)construction

Recepción: 20/03/2020

Evaluación: 17/04/2020

Aceptación: 28/05/2020

Artículo de Investigação - Revisión

https://doi.org/10.19053/01227238.11928

Teresa Sarmento ${ }^{1}$

Universidade do Minho, Portugal

https://orcid.org/0000-0002-2371-399X

Rosana Maria Martins ${ }^{2}$

Universidade Federal Mato Grosso, Brasil

http://orcid.org/0000-0002-2217-7531

Simone Albuquerque Rocha ${ }^{3}$

Universidade Federal Mato Grosso, Brasil https://orcid.org/0000-0003-4140-8830

Conceição Leal da Costa ${ }^{4}$

Universidade de Évora, Portugal https://orcid.org/0000-0003-3299-6845

\section{RESUMO}

As céleres mudanças do mundo repercutem na (re)construção de saberes, contemporâneo requerem dos professores novos saberes, teorias, experiências e valores que lhes permitam (re)ver e transformar suas práticas, na complexa tarefa de melhorar a qualidade social da educação, o que passa necessariamente pela formação e pela experiência profissional. Este cenário motivou a presente pesquisa objetivando compreender como

na ação profissional e na (re)constituição da identidade docente, as alterações ocorridas nas últimas décadas, as políticas educacionais, legislação, alterações e mudanças institucionais, acordos internacionais e, sobretudo, as experiências pessoais e profissionais de cada docente. Entre as quatro dimensões que o projeto aborda - formação, experiência, interações

1 Doutora em Estudos da Criança. Investigadora do Centro de Investigação em Estudos da Criança (CIEC). Membro do Departamento em Ciências Sociais da Educação, Instituto de Educação, Universidade do Minho (UMinho), Portugal. Correiro eletrômico: tsarmento@ie.uminho.pt.

2 Doutora em Educação. Departamento de Educação. Universidade Federal de Rondonópolis-MT (UFR), Brasil. Grupo de Pesquisa InvestigAção. Correio elerônico: rosana.martins@ufr.edu.br.

3 Doutora em Educação. Departamento de Educação. Universidade Federal de Rondonópolis-MT (UFR), Brasil. Correio elerônico: sa.rocha@terra.com.br.

4 Doutora em Ciências da Educação. Departamento de Pedagogia e Educação. Universidade de Évora (UÉvora), Portugal. Correiro eletrômico: mclcosta@uevora.pt. 
einserção em organizações-selecionou-se para este texto a experiência, enquanto constitutiva dos saberes da prática e da identidade profissional. A pesquisa conta com investigadoras das Universidades do Minho-Pt, de Évora-Pt e da UFR/UFMT/ Br. O corpus da pesquisa constitui-se de narrativas de três professores de crianças, uma do Brasil e duas de Portugal, com 20 a 30 anos de ação/prática docente, considerados como bons professores pela comunidade profissional. Questiona-se: Quais as aprendizagens mais significativas identificadas pelos professores e como as relacionam à experiência profissional? Como é que a experiência se constitui como formação profissional? Quais as experiências com crianças que os professores reportam como mais significativas? A pesquisa comprova que, independentemente de qual o lado do Atlântico em que se esteja, as interações com as crianças, com os pares profissionais e com as comunidades, constituem o pilar principal para a (re)construção das identidades profissionais.

Palavras-chave: Narrativas biográficas; formação; experiência docente; interação educativa; identidade profissional.

\section{RESUMEN}

El objetivo de la presente investigación es comprender cómo afectan la (re)construcción del conocimiento, la acción profesional y la (re)constitución de la identidad docente, los cambios ocurridos en las últimas décadas, las políticas educativas, la legislación, los cambios institucionales, los acuerdos y las experiencias personales y profesionales de cada profesor. Originalidad: entre las cuatro dimensiones que aborda el proyecto (capacitación, experiencia, interacciones e inserción en las organizaciones), seleccionamos la abordagen de la experiencia, focando la articulación entre el conocimiento de la práctica y la identidad profesional. Método: La investigación narrativa cuenta con investigadores de las universidades de Minho-Pt,
Évora-Pt y UFR / UFMT / Br. Como estrategia optamos por constituir lo corpus de la investigación con narraciones de tres maestros de niños, uno de Brasil y dos de Portugal, con 20 a 30 años de práctica docente. La pregunta es: ¿Cuáles son los aprendizajes más significativos identificados por los maestros? ¿Cómo se constituye la experiencia como formación profesional? ¿Qué experiencias con los niños informan los maestros como las más significativas? En conclusión, la investigación demuestra que las interacciones con niños, pares profesionales y comunidades son el pilar principal para la (re) construcción de identidades profesionales.

Palabras clave: Narrativas biográficas; formación; experiencia docente; identidad profesional; interacciones educativas.

\section{ABSTRACT}

The objective of the current research seeks at understanding how affects the knowledge re-construction, the professional action and the reconstitution of the teaching identity, the changes that have taken place in the last decades, the educational policies, the legislation, institutional changes, agreements, and the personal and professional experiences of each teacher. Originality: among the four dimensions that the project addresses (teaching development, experience, interactions and inclusion into organizations), we selected the approach of experience, focusing on the joint of knowledge of practice and professional identity. The method: The narrative research has researchers from the universities of Minho-Pt, Évora-Pt and UFR / UFMT / $\mathrm{Br}$. As strategy, we opted to constitute the research corpus with narratives from three teachers of children. One from 
Brazil and two from Portugal, with 20 to 30 years of teaching practice. The question is, what are the most significant learnings identified by teachers? How is experience constituted as professional development? What experiences with children do teachers report as the most significant? To conclude, research shows that interac- tions with children, professional peers, and communities are the main pillar for the (re) construction of professional identities.

Key words: Biographical narratives; teaching development; teaching experience; professional identity; educational interactions.

\section{INTRODUÇÃO}

A presente pesquisa objetiva compreender como repercutem na (re)construção de saberes, na ação profissional e na (re)constituição da identidade docente, as alterações ocorridas nas últimas décadas, as políticas educacionais, legislação, alterações e mudanças institucionais, acordos internacionais, e, sobretudo, como estas influenciam as experiências pessoais e profissionais de cada docente. Trata-se de pesquisa em andamento, que integra três instituições, com investigadoras das Universidades do Minho-Pt, de Évora-Pt e da Federal de Mato Grosso/Câmpus Universitário de Rondonópolis/Br . A escrita do texto carrega nuances das formas de registro de Portugal e do Brasil. Neste texto, analisamos as narrativas de três professoras de crianças dos 3 aos 12 anos de idade, sendo um atuante no Brasil e duas em Portugal. Esses profissionais têm entre 20 e 30 anos de ação/prática docente, sendo considerados como bons professores pela comunidade educacional.

Pesquisar sobre as experiências que constituem a profissionalidade docente requer envolver, no estudo, não somente a formação inicial e continuada, assim como em que sentido as mudanças sociais no cenário nacional e internacional as afetam, apontando, ainda, possíveis alterações nos processos de formação e desenvolvimento pessoal e profissional do futuro docente "na profissão de ensinar e fazer aprender" ${ }^{\prime \prime}$.

Portanto, não se trata de discutir somente a formação centrada no saber ou no fazer, mas em processos que se voltam e podem implicar o desenvolvimento humano, a capacidade de enfrentamento da diversidade e da complexidade do mundo, as contradições e desafios que assolam a sociedade e as relações educacionais e, por conseguinte, os profissionais da educação. Sob esse aspecto, não se pode desconsiderar o conhecimento da realidade escolar que se configura de extrema importância para a inserção do futuro professor nos problemas da comunidade escolar. Para tanto, "é preciso refletir sobre esta dimensão por meio de propostas curriculares, de atividades que permitam a compreensão da dinâmica e das relações que ali se estabelecem" ${ }^{\prime \prime}$, procurando analisar como a

5 Leas das Graças Camargo Anastasiou, “Trilhas para análise da formação docente, inicial e continuada”, en Desafios e trajetórias para o desenvolvimento profissional docente, eds. Marielda Ferreira Pryjma (Curitiba: Ed. UTFR, 2013), 11.

6 Evandro Ghedin, Maria Isabel de Almeida; Yoshie Ussami Ferrari, "Formação de professores". Caminhos e descaminhos da prática. (Brasília: Líber Livro, 2008), 32. 
experiência que cada um vive em contexto educativo, quando sujeita à reflexão, pode constituir-se como nova aprendizagem e construção de novos saberes profissionais.

Comprendendo que a aprendizagem da docência não se dá efetivamente só na escola e nas relações ali estabelecidas, constatamos que esta se inicia muito antes do exercício profissional, desde os tempos em que ingressamos numa sala de aula, e continua ao longo de nossas vivências profissionais. Nesse entendimento, "trata-se, portanto, de um conjunto de processos que envolve conhecimentos teóricos e práticos, oriundos das experiências passadas e atuais" ${ }^{\prime 7}$. Assim, ao tentarmos compreender as experiências e práticas dos professores ao longo da formação e carreira docente, devemos considerar, também, "as 'aprendizagens por observação', como sendo dados importantes e necessários para o processo formativo de mudanças nas teorias pessoais" ${ }^{\prime \prime}$.

Nesse sentido, o processo de apreender a experiência constitutiva da prática docente implica observar como os professores se formam, como refletem sobre si e sua prática, sobre suas experiências e as relações que atribuem sobres estas e o espaço em que elas se dão - a escola e seu entorno. Assim pensando, os professores que refletem sobre suas experiências, ampliam e oxigenam seus saberes da formação e da prática docente durante toda a carreira docente, em um continuum?.

Diante do exposto, a pesquisa investiga como a experiência, constitutiva do desenvolvimento profissional dos professores com mais de 20 anos de magistério, promove-os identitariamente ao longo da prática. Isto significa trazermos à socialização da comunidade docente, de que forma as vivências tornadas experiência têm sido um fator relevante nas aprendizagens bem sucedidas de tais profissionais. Considera-se, então, que estamos pesquisando profissionais que foram apontados pela escola, por seus pares e comunidade escolar, como professores referência em práticas, saberes e sucessos de aprendizagem com crianças. Em face destes posicionamentos, elencamos alguns questionamentos: Quais as aprendizagens mais significativas identificadas pelos professores e como as relacionam à experiência profissional? Como é que a experiência se constitui como formação profissional? Quais as experiências com crianças que os professores reportam como mais significativas?

A constução do texto a oito mãos - uma pesquisadora da Universidade do Minhos, duas da Universidade Federal de Rondonópolis e uma da Universidade de Évora - faz parte de uma investigação em curso, que desenvolve o seu caminho de reflexão e construção de conhecimento a partir de um círculo de estudos e de produções geradas a partir do corpus da pesquisa ${ }^{10}$.

7 Aline Maria de Medeiros Rodrigues Reali e Claudia Raimundo Reyes, C. R. "Reflexões sobre o fazer docente". (São Carlos: EdUFSCar, 2009), 13.

8 Aline Maria de Medeiros Rodrigues Reali., Regina Maria Tancredi e Maria Graça Mizukami. "Programa de mentoria online: espaço para o desenvolvimento profissional de professoras iniciantes e experientes”. Revista Educação e Pesquisa, v.34, n¹ (2008): 21.

9 Maria Graça Mizukami. et al. "Escola e aprendizagem da docência: processos de investigação e formação. (São Carlos: EdUFSCar, 2003).

10 Teresa Sarmento, "Infâncias e crianças em narrativas de educadoras de infância", en. Pesquisa (auto)biográfica, infâncias, escola e 
Martins (2018) crê ser importante "o estudo das narrativas autobiográficas sobre professores experientes bem-sucedidos, que já vivenciaram tensões e aprendizagens intensivas nos contextos, muitas vezes, marcadas por caminhos desconhecidos e conflituosos"11. Acreditamos que a aprendizagem docente acontece no decorrer da trajetória do indivíduo e envolve sua história de vida, em especial, a escolar, a formação inicial e continuada.

\section{O que nos vai acontecendo com o que fazem conosco...}

Parafraseando o título do texto, usamos esta frase no mesmo sentido: o que nos acontece e isso significa descrever, no caso da presente pesquisa, como as aprendizagens experienciais ${ }^{12}$, por nós também designadas como experiências formadoras, e vivenciais na docência foram transformando os professores em profissionais do ensino, evidenciando de que maneira as aprendizagens da formação inicial os foram constituindo e como o processo iniciático da docência foi, por eles, sentido, tendo em vista sua trajetória de formação, o currículo vivenciado, a forma como isso foi notado e vivido e como isso "se nos aconteceu".

Nos últimos anos as perspectivas interpretativas e hermenêuticas rompem com a ciência positivista, em busca à compreensão dos fenômenos humanos, dos testemunhos de vida. Compreendemos que mesmo que haja muitas concepções para a palavra experiência, os autores que se debruçam por essa temática não a conceituam de forma dissociada dos saberes, sendo esses considerados como fundamentais.

É importante ressaltar que buscamos romper com a lógica que considera experiência como tudo aquilo que se vive na prática e o saber da experiência como acumulação de saberes práticos, de saber o que e como fazer em situações concretas. Nossa compreensão perpassa na abordagem que considera que a experiência está sempre vinculada ao saber, isto é, ao saber da experiência, ao que é introduzido no acontecer das coisas para significá-lo, problematizá-lo

diálogos intergeracionais Passeggi, Furnaletto e Palma (Org.). (Curitiba: Editora CRV, 2016):77-94. http://hdl.handle.net/1822/52497; Teresa Sarmento; Simone Albuquerque da Rocha; Rosana Maria Martins, "O que fazemos com o que fazem conosco... como nos formamos ao longo da nossa trajetória profissional”, en Actas do III Congresso Nacional de Formação de Professores e XIII Congresso Estadual Paulista sobre Formação de Educadores (CEPFE), (Águas de Lindóia, SP, 2016). Disponible sur: http://unesp. br/anaiscongressoeducadores (6120-6131). http://hdl.handle.net/1822/52538; Simone Albuquerque da Rocha; Teresa Sarmento; Conceição Leal da Costa e Rosana Mara Martins, "O que fazemos com o que fazem conosco ... identidades em (re)construção", en Atas VII Congresso Internacional de Pesquisa (Auto)biográfica - CIPA. (Cuiabá, 2016). Simone Albuquerque da Rocha; Teresa Sarmento; Conceição Leal da Costa e Rosana Mara Martins e Isa Mara C. S. Domingues, "O que fazemos com o que fazem conosco... a formação e a experiência no contexto de desenvolvimento profissional de professores", en Anais... Congresso Educação e Diversidade - CONPeduc. (Rondonópolis, 2016); Rosana Maria Martins, "As experiências iniciais na docência como contributos do processo de vir a ser professoras experientes bem-sucedidas”. Anais... Anais... VIII Congresso Internacional de Pesquisa (Auto) Biográfica (CIPA). (São Paulo:UNICID, 2018); Marly Souza Brito Farias e Rosana Maria Martins, "A profissionalização docente de professoras alfabetizadoras em narrativas autobiográficas", en Anais... Anais... VIII Congresso Internacional de Pesquisa (Auto) Biográfica (CIPA). (São Paulo:UNICID, 2018).

11 Rosana Maria Martins, "Nada é mais formativo do que a própria formação acadêmica associada às experiências e à prática: narrativas autobiográficas de uma professora experiente", en Anais... VIII Congresso Internacional de Pesquisa (Auto)Biográfica (CIPA). (São Paulo:UNICID, 2018), 8.

12 Christine Josso, Experiências de Vida e Formação.Tradução José Cláudio e Júlia Ferreira. São Paulo Cortez, 2004. 
ou iluminá-lo. Larrosa afirma que passar pela experiência é sair transformado dela ${ }^{13}$.

Como Contreras ${ }^{14}$, compreendemos que o saber tem sua origem no modo de viver a educação, não enquanto o que vai se sucedendo no contexto, mas aquele que envolve o pensar educativo, a fim de se obter uma maior compreensão dos acontecimentos que vivenciamos. Nesta direção, o conhecimento pedagógico necessita partir da experiência, oportunizando voltar ao que foi vivido com sensibilidade, consciência e abertura a novas aprendizagens.

Assim, parece-nos coerente trazer para o bojo destas reflexões as contribuições de Josso ${ }^{15}$ que nos revela o conceito de experiência como algo que vai se juntando e transformando o conhecimento no decurso da vida, a partir do exercício da escrita e escuta de si.

A autora amplia a questão da centralidade do sujeito nos processos de formação, possibilitando o olhar sob o ponto de vista do aprendente, em interações com outras subjetividades.

Nesta perspectiva, salientamos que para ser experiência: há que se voltar a pensar $^{16}$. Este entendimento seria, pois, um argumento suficiente para defender o olhar que assumimos para pensar o corpus da pesquisa, a partir da perspectiva da interpretação do vivenciado.

Todo esse processo, então, corporificado nas professoras da pesquisa, somado às diferentes experiências, espaços e contextos de suas práticas, tornaram-nas docentes bem-sucedidas. A pesquisa, portanto, toma como bem-sucedidas aquelas profissionais com mais de 20 anos de docência e que, ao longo de sua carreira, visam ao êxito do ato educativo. Assim, aprimoram seus saberes e os recursos intelectuais dos alunos, proporcionando-lhes novos desafios. Para Santos, pode-se considerar, "sob a ótica do significado e do sentido do trabalho docente, que as evidências apontam como professores bem-sucedidos aqueles que conseguem integrar significado e sentido em suas práticas cotidianas em sala de aula, ou seja, descobrem o que os motivam, o que os incitam ao [...]"17, desenvolvimento profissional num continuum.

Monteiro explica que "a articulação de saberes obtidos na história de vida com os adquiridos no exercício da profissão indica a formação de um jeito próprio de se trabalhar, constituindo a "personalidade profissional"18. De acordo com as autoras, somente com o passar do tempo, é que os educadores se tornam

13 Jorge Larrosa, "Notas sobre narrativa e identidade (a modo de presentación", en A aventura (auto)biográfica: teoria e empiria, org. Maria Helena Menna Barreto Abrahão (Porto Alegre: EDIPUCRS, 2004), 11-27.

14 José Contreras Domingo, “Ter histórias para contar: aprofundar narrativamente a educação", en Roteiro, Joaçaba, v. 41, n. 1 (jan./abr (2016), 15-40.

15 Marie-Christine Josso, “Experiências de Vida e Formação”.Tradução José Cláudio e Júlia Ferreira. (São Paulo Cortez, 2014).

16 Jorge Larrosa, "Notas sobre narrativa e identidade (a modo de presentación”, en A aventura (auto)biográfica: teoria e empiria, org. Maria Helena Menna Barreto Abrahão (Porto Alegre: EDIPUCRS, 2004), 11-27.

17 Maricéa do Sacramento Santos, Reflexões e prática de uma professora bem-sucedida. Dissertação (Mestrado em Educação). Universidade Federal de São João Del-Rei. (2010), 49

18 Maria Iolanda Monteiro, “ Histórias de vida de alfabetizadoras bem-sucedidas no períood de 1950 a 1980”, en Desenvolvimento profissional da docência: teorias e práticas, organizado por Maria Graça Mizukami e Aline Maria de Medeiros Rodrigues Reali. (São Carlos: EduFSCar, 2012), 109 
bem-sucedidos e reconhecidos por outros ${ }^{19}$. Para elas, é na relação existente entre os saberes e as práticas realizadas na trajetória de vida que possibilitarão a formação, a mudança e a transformação do saber trabalhar ${ }^{20}$.

Tendencialmente vista do exterior e durante muitos anos ao jeito mecanicista, a profissão docente é hoje estudada, também, em linhas de investigação que recorrem ao que os professores dizem e contam de si. Dessa forma, assume-se a sua capacidade para desvendarem fenômenos de interação, perceber a evolução das representações e dos significados atribuídos pelos autores em situação de relação social e para se apreender o modo como vivências antigas se refletem nas atuais.

Para este estudo, considera-se, ainda, que a formação, seja inicial e/ou continuada, não é a única fonte de aprendizagem da docência, mas também as relações que os professores estabelecem entre seu tempo de atuação docente, as experiências constitutivas de sua prática, os processos reflexivos sobre a docência e a realidade educacional e social ${ }^{21}$. A ideia de que os professores, ao falarem sobre as suas experiências profissionais, escolhem gêneros narrativos e que essas histórias encerram possibilidades de entendermos o seu desenvolvimento profissional, situado na história mais ampla das suas vidas, articulando o passado com o presente cujas influências mútuas se deixam notar ${ }^{22}$, justificam a nossa abordagem narrativo-biográfica neste estudo. Acrescentando o que refere Josso $^{23}$, assumimos que vivência e experiência se podem relacionar em processos de transformação que emergem no próprio viver, fazer e experienciar, em função do que cada um fizer dessa vivência, ou seja, de se refletir sobre a mesma, uma vez que "a experiência requer significados novos para o vivido" 24 .

Não se trata de compreender o termo experiência como tudo aquilo que se vive na prática e o saber da experiência como acumulação de saberes práticos, de saber o que e como fazer em situações concretas. Pelo contrário, vamos intuindo que há uma dialética entre a experiência e o pensamento, criando movimentos de interação entre os mesmos. Pensamos porque algo nos ocorre; pensamos como fruto das coisas que nos passam, a partir do que vivemos, como consequência do mundo que nos rodeia, que experimentamos como próprio, afetados pelo que nos passa.

19 Ibid

20 Ibid

21 Teresa Sarmento, "Aprender a profissão em diferentes espaços da vida". Revista de Educação PUC Campinas, 18(3) (2013). Conceição Leal da Costa, C. "Viver Construindo Mudanças - a vez e a voz dos professores. Contributo para os estudos da aprendizagem e desenvolvimento dos professores". (Tese de Doutoramento: Universidade de Évora, 2015). O Kelchtermans. "O comprometimento profissional para além do contrato: autocompreensão, vulnerabilidade e reflexão dos professores", en Methodological Advances in Research on Emotion and Education, editadp por M. Zembylas and P.A. Schutz. (Switzerland: Springer International Publishing, 2016)

22 E. Michael Connelly e D. Jean Clandinin, "Stories of experience and Narrative Inquiry". Educational Researcher, Vol. 19, No. 5 (Jun. - Jul., 1990), 2-14.

23 Marie-Christine Josso, "Experiências de Vida e Formação"Tradução José Cláudio e Júlia Ferreira. (São Paulo Cortez, 2014).

24 José Contreras Domingo e Nuria F. Pérez de Lara (Comps). “Investigar la experiência educativa”. (Madrid: MORATA, 2010$), 25$. 
Esclarecem Contreras e Pérez de Lara ${ }^{25}$ que a reflexão, sobre o sentido educativo das experiências, vai desde a visão pedagógica que se tem e colocam o sujeito da aprendizagem em jogo consigo mesmo, com suas ideias, aspirações, formas de entender e fazer educação. E, no processo investigativo, as aspirações os encaminham a novas experiências e compreensões do que supõem ser o processo educativo, no desejo de entender o que não se havia entendido, por isso se investiga, para compreender ou ver de uma nova maneira algo que até então era incompreensível.

No fundo, vivendo, aprendem construindo as mudanças, de si e de outros, desenvolvendo-se a pessoa e a profissional que se entrelaçam em teias relacionais ${ }^{26}$, aspectos também evidentes em textos como os de Sarmento T., Leal Costa, Goodson ou Kelchtermans ${ }^{20}$, entre muitos outros.

Neste sentido, os participantes desta pesquisa apresentam sua perspectiva experiencial narrada, oralmente, por si mesmos. Nas entrevistas narrativas, a abordagem biográfica valida o seu conhecimento sobre a educação e o ensino, na medida em que seus saberes são considerados e partilhados, oferecendo oportunidades para o estudo de histórias pessoais em termos de passado e presente, oportunizando o planejamento de experiências profissionais futuras ${ }^{27}$. Numa recolha de textos, Nóvoa e Finger ${ }^{28}$ deram a conhecer um conjunto de pesquisadores que buscaram, em seus estudos, entender o que o adulto tinha a dizer sobre suas experiências e o que podiam fazer com elas ${ }^{29}$. A estes autores, podemos juntar estudos e autores como Dominicé, Pineau, Passeggi, Delory-Momberger ${ }^{30}$, entre muitos outros, como importantes impulsionadores do movimento biográfico internacional, o qual tem avançado tanto no sentido de conceber a especificidade epistemológica das narrativas de si como prática de formação, como nas formas de produzir conhecimento em Educação. No Brasil, desde a última década do século $\mathrm{XX}$, constatamos os interesses crescentes e trabalhos que, "baseados nas histórias de vida como método de investigação qualitativa e como prática de formação, procuram identificar, nas trajetórias de professores, questões de interesse para a pesquisa educacional"31.

25 Ibid

26 Teresa Sarmento 2013. "Aprender a profissão em diferentes espaços da vida.. en Revista de Educação PUC Campinas, 18(3), (20130, p. Suprimidas, Leal da Costa 2015. Título. Tese de Doutoramento: Universidade de Évora. Goodson, I. F. 2013. Developing narrative theory. London: Routledge ou Kelchtermans, O comprometimento profissional para além do contrato: autocompreensão, vulnerabilidade e reflexão dos professores. In: M. Zembylas and P.A. Schutz (eds.). Methodological Advances in Research on Emotion and Education. (Switzerland: Springer International Publishing, 2016), 31-42.

27 Rosana Maria Martins, "Aprendendo a ensinar: as narrativas autobiográficas no processo de vir a ser professora" (Tese de Doutoramento em Educação: Universidade Federal de São Carlos, 2015).

28 António Nóvoa e Matthias Finger (orgs.). “O método (auto) biográfico e a formação”. (Natal: EDUFRN; São Paulo: Paulus, 2010), 155-187.

29 Ibid.

30 Pierre Dominicé, “O processo de formação e alguns dos seus componentes relacionais", en O método (auto)biográfico e a formação, António Nóvoa e Matthias Finger (orgs.). (Natal: EDUFRN; São Paulo: Paulus, 2010). (Natal, RN: EDUFRN; São Paulo: Paulus, 2010). Gaston Pineau, "As histórias de vida em formação: gênese de uma corrente de pesquisa-ação-formação existencial . Maria Conceição Passeggi, "Narrativas da experiência na pesquisa-formação: do sujeito epistêmico ao sujeito biográfico", en Roteiro, Joaçaba, v. 41, n. 1 (jan./abr 2016), 15-40. Christine Delory-Momberger, .'Abordagem metodológica na pesquisa biográfica". Revista Brasileira de Educação, v. 17, n. 51, (set./dez., 2012) , 523-740.

31 Maria Conceição Passeggi, Elizeu Clementino de Souza e Paula Perini Vicentini, “Entre a Vida e a Formação: Pesquisa (auto)Biográ- 
Existe, pois, um recurso crescente às "narrativas da experiência profissional ou existencial e aos fatos pessoais vividos" ${ }^{\prime 32}$. Na perspectiva recente de um dos autores acima mencionados, a narrativa biográfica pode ser definida como "biografia educativa" por fazer entrada na trajetória educativa dos sujeitos, focalizando, predominantemente, as experiências de formação de quem as vivencia $^{33}$. Como alude Josso, ao olhar a formação sob o ponto de vista daquele que aprende, as experiências formadoras implicam "uma articulação conscientemente elaborada entre atividade, sensibilidade, afetividade e ideação" ${ }^{34}$. Por tal, prosseguindo nesta linha, retomamos autores anteriormente citados para afirmarmos que "essa articulação objetiva-se tanto numa representação quanto numa competência e é justamente o que dá o status de experiência às nossas vivências" ${ }^{\prime 35}$.

É tendo em conta esses olhares que, no estudo que desenvolvemos e aqui apresentamos, elegendo como enfoque a experiência, entendemo-la enquanto constitutiva dos saberes da prática e de (re)construção da identidade no decorrer de um percurso profissional. Ao insistirmos no prefixo (re), pretendemos salientar como a experiência refletida é capaz de dinamizar novas formas de pensar, de fazer e, até, de ser enquanto profissional.

\section{O caminho da pesquisa... a arte de refletir sobre as próprias experiências}

A pesquisa, no âmbito do projeto de investigação $\mathrm{O}$ que fazemos com o que fazem conosco... identidades em (re)construção, aborda a experiência de docentes, enquanto constitutiva dos saberes da prática e da identidade profissional. Nesse sentido, atribui importância ao adotar a narrativa biográfica como importante instrumento para compreender o que a experiência vai fazendo com os professores... como ela os constitui. Esse processo de narrar-se consiste em importante elemento para compreender o sujeito biográfico, pois, conforme Passeggi, ele se constitui "pela narrativa e na narrativa, na ação de pesquisar, de refletir e de narrar: como ator, autor e agente social" ${ }^{\prime 36}$. Por outras palavras, a nossa perspectiva vai contra "o caráter técnico do ensino e à maneira fragmentada de tratar a relação da pessoa com os saberes e consigo mesma, adotada por abordagens que negligenciam a palavra dos protagonistas sobre a ação educativa" ${ }^{\prime 37}$. Neste texto, com um corpus de pesquisa mobilizado nas narrativas

fica, docência e Profissionalização". Educação em Revista, 27 (1) (2011), 370.

32 Maria Conceição Passeggi, "Narrativas da experiência na pesquisa-formação: do sujeito epistêmico ao sujeito biográfico", en Roteiro, Joaçaba, v. 41, n. 1, p. 15-40, (jan./abr, 2016), 69-70

33 Pierre Dominicé, “O processo de formação e alguns dos seus componentes relacionais”, en O método (auto)biográfico e a formação, Finger, Matthias e Antonio Nóvoa. (Natal, RN: EDUFRN; São Paulo: Paulus, 2010).

34 Marie-Christine Josso, Experiências de Vida e Formação.Tradução José Cláudio e Júlia Ferreira. (São Paulo Cortez, 2014$)$, 48.

35 Maria Conceição Passeggi, Elizeu Clementino de Souza e Paula Perini Vicentini, “Entre a Vida e a Formação: Pesquisa (auto)Biográfica, docência e Profissionalização”. Educação em Revista, 27 (1) (2011), 374.

36 Maria Conceição Passeggi, "Narrativas da experiência na pesquisa-formação: do sujeito epistêmico ao sujeito biográfico", en Roteiro, Joaçaba, v. 41, n. 1 (jan./abr, 2016), 69-70.

37 Maria Conceição Passeggi, Elizeu Clementino de Souza e Paula Perini Vicentini, “Entre a Vida e a Formação: Pesquisa (auto)Biográfica, docência e Profissionalização". Educação em Revista, 27 (1) (2011), 375. 
de três docentes, sendo 01 do Brasil e 02 de Portugal, professoras cujos nomes ficcionados são Helena, Graça e Ádria.

A identificação dos professores foi realizada de forma deliberada, por consulta a vários elementos (colegas, gestão da escola, sindicatos), de modo a garantirmos a certeza de estarmos perante profissionais ativos na sua permanente construção profissional. Baseadas na consciência de que "história implica passado, implica experiência" 38 definimos à partida que tínhamos para selecionar professoras com um tempo alargado de serviço. Ao mesmo tempo, acreditando que "as identidades são entendidas como construções realizadas pelo próprio agente social na interação com a multiplicidade de contextos de que participam" ${ }^{\prime \prime}$, antecipamos escolher professoras com um número dilatado de experiências socioprofissionais. Ainda que o investimento profissional seja um indicador muito subjetivo, realçamos como critérios, para essa seleção, o reconhecimento dos pares, a inserção em projetos de animação comunitária, a participação em investigações, a seleção das suas escolas para a cooperação em estágios, as representações sociais que existem sobre as mesmas.

Como já dissemos, metodologicamente optamos pelas narrativas biográficas. Galvão comenta que, quando falamos de narrativa, temos de esclarecer o seu significado $^{40}$. Assim, a autora, baseando-se em Stephens, afirma que a narrativa está imbricada a três componentes assim descritos: "a História - abrange as personagens envolvidas em determinados acontecimentos, num espaço e tempo determinados e possibilita uma primeira interpretação do que é contado" ${ }^{\prime 4}$. A seguir, cita "o "Discurso - forma específica como qualquer história é apresentada; Significação - uma interpretação de segundo nível que o ouvinte/leitor/ espectador" 42 afirma se efetivar a partir do inter-relacionamento da história e do respectivo discurso. O sujeito, ao narrar-se, projeta imagens relatadas segundo a forma como ele próprio se vê, como se fosse num espelho (speculum em latim, que significa representação, reflexo). Mas a leitura dessa imagem também pode ser concebida como uma imagem invertida, isto é, a imagem de si que se modifica ao narrar-se ao outro ${ }^{43}$.

Intencionalmente, e porque expor a sua vida implica desgastes emocionais que podem ser agravados se o espaço onde é feito oferecer alguns constrangimentos, as entrevistas foram realizadas no recinto de trabalho das entrevistadas, também para, enquanto investigadoras, podermos conhecer o ambiente educativo em que as mesmas lecionam, procurando deixá-las o mais à vontade possível ao narrarem espaços-tempos das suas vidas. A entrevista foi realizada em dois momentos, mediados por um espaço de duas a três semanas, de forma

38 Teresa Sarmento, "Contextos de vida e aprendizagem da profissão", en Formação de professores. Aprendizagem profissional e acção docente, Julia Formosinho. (Porto: Porto Editora, 2002), 273.

39 Ibid.

40 Cecilia Galvão, "Narrativas em educação. Ciência \& Educação". v. 11, n. 2, (2005), 328.

41 Ibid

42 Ibid

43 Simone Albuquerque da Rocha, "Formação de licenciandos e constituição da identidade docente". Relatório de Pós-Doutorado, PUC-SP, Programa de Pós-Graduação em Educação e Psicologia. São Paulo, 2011, 
a possibilitar a transcrição da entrevista, a sua devolução às entrevistadas para alguma ratificação e mobilização de novas memórias, com base na defesa feita por Nóvoa, pois, numa metodologia qualitativa, deve-se manter "uma responsabilidade social e ética (que) obriga o investigador a uma vigilância crítica sobre si próprio" ${ }^{44}$, cuja observação se notou também em Leal da Costa e Biscaia (2012). Por outro lado, cuidou-se para que a investigação se desse de forma colaborativa e com "envolvimento mútuo" 45 , e, para isso, o avanço da investigação dependeu da mútua concordância entre investigador e respondente ${ }^{46}$. No primeiro tempo de entrevista, as questões foram lançadas de maneira muito aberta, flexível, numa busca de interações orais diretas, geradoras de confiança e de produção de informações, conforme orientam Cohen e Manion, Poirier, Clapier-Valladon e Rayband, assim como Bertaux ${ }^{47}$, entre outros. Cada entrevista foi, então, transcrita e sujeita a uma análise flutuante, no sentido de realizá-la com alguma leveza, sem estar sujeita a grandes categorizações, mas no sentido de irmos nos apropriando dos conteúdos e do sentido das mesmas. $\mathrm{O}$ segundo momento, norteado por essa análise prévia, já foi mais direcionado, procurando delimitar questões concretas que nos ajudassem a garantir a recolha de dados respondentes aos objetivos pré-definidos no desenho da investigação.

\section{Como é que estas professoras se tornaram bem-sucedidas? O que fazem com o que fizeram a elas?}

Compreendemos que identidade docente se dá ao longo de um processo, em que cada indivíduo se apropria do sentido da sua história pessoal e escolar, sobretudo, no contato do futuro professor com a prática profissional, em que atividade docente marca trajetórias diferenciadas dessa identidade.

Portanto, não deixa de ser um processo complexo que requer tempo, ou seja, o tempo permite refazer identidades, para acomodar inovações e assimilar mudanças $^{48}$.

A identidade docente se constitui como uma interação entre o sujeito e suas experiências individuais e profissionais, ou seja, a identidade é construída e transmitida ${ }^{49}$.

44 António Nóvoa, A. 1991. “O passado e o presente dos professores", en Profissão Professor, organizado por António Nóvoa. (Porto: Porto Editora, 1991), 37.

45 Conceição Leal da Costa e Constança Biscaia, "Um olhar em torno de possibilidades de conhecer a diferença de forma diferente”, en Notas de uma investigação com narrativas de vida, Coordenação de L. Del Río, L. Bermudez e P. Àlvarez Teva (Coord). FECIES. (Granada: Asociación Española de Psicología Conductal, 2012), 1359-1365.

46 E. Michael Connelly e D. Jean Clandinin, "Stories of experience and Narrative Inquiry". Educational Researcher, Vol. 19, No. 5 (Jun. - Jul., 1990), 4.

47 L. Cohen e L. Manion, “Métodos de Investigación Educativa”, Madrid: Muralla, 1990 e Poirier, J., Clapier-Valladon, S. e Raybant, P.. "Histórias de Vida - Teoria e Prática. Oeiras: Celta Editora, 1995. D. Bertaux "Les récits de vie". Paris: Nathan, 1997.

48 António Nóvoa, “Os professores e as histórias da sua vida”, en Vida de professores. Organizado por António Nóvoa. (Portugal: Porto, 2000), 11-30.

49 Carlos Marcelo, "A identidade docente: constantes e desafios". Revista Brasileira de Pesquisa sobre Formação Docente. Belo Horizonte, v.01, n. 01 (ago./dez 2009), 109-131. 
As narrativas biográficas colaboram para a compreensão sobre o que o sujeito-professor expressa acerca de seus sentimentos, representações e percepções que emergem nesse processo de formação e autoformação ${ }^{50}$. Constituem-se em importantes dispositivos para "contar a vida", necessidade esta que acompanha o próprio viver, pois "[...] contamos coisas que passam e coisas que não nos passam. Contá-las e contarmo-nos não significa necessariamente compreendê-las, compreendemos que há algo a contar-se em relação a algumas das coisas que vivemos e que afetam nosso viver" ${ }^{\prime \prime}$.

Nas narrativas que recolhemos é possível identificar a experiência enquanto constitutiva dos saberes da prática e da identidade profissional. Assim, afirma Helena:

\begin{abstract}
A própria experiência [é formativa] aprendemos sempre todos os anos com novos pais, com novas crianças, com novos desafios que nos surgem, com a busca que temos de ir ao alcance, à procura de alguma formação que nos ajude a lidar com alguma dificuldade que nós ainda sentimos ou que achamos que é, que ainda precisamos de saber mais sobre as coisas, portanto... também, também...[...] Mas, nas imensas situações em que me ajudam...eu gosto de chegar a casa e passar um bocadinho o meu dia, e perceber um bocadinho o que é que foi o meu dia, em que é que eu poderei estar a falhar mais ${ }^{52}$.
\end{abstract}

A professora expressa o valor das interações com diferentes tipos de pais. Na medida em que a obrigam a flexibilizar formas de atuações e a rever as suas próprias concepções educativas - abrindo-se a novos entendimentos sobre diferentes aspectos, ou assumindo maior assertividade no jeito de apresentar os seus argumentos, a sua experiência vai emergindo. Além disso, revela a tomada de consciência de que a profissionalização é permanente, que é preciso estar-se sempre numa atitude de pesquisa, o que também parece ser um válido contributo nas mudanças que se vão operando no seu contexto de trabalho com as crianças. Um outro dado interessante foi o de Helena refletir sobre sua prática naquele dia. A reflexão sobre a prática é importante para revigorar a experiência e incorporar o que dela pode servir como aprendizagem profissional perante a incerteza dos acontecimentos. Podendo ser mobilizada de novo em situações posteriores, constitui-se em uma modificação na forma de lidar com situações que se repetem e, portanto, garante uma mudança securizante. Sobre esta experiência e seu significado na prática docente, Ádria, assim, expressa:

Apesar de a docência ser uma profissão que lida permanentemente com o inesperado, penso que a experiência seja um componente extremamente importante no cotidiano profissional. A experiência nos permite lidar melhor com as crianças, com

50 Elizeu Clementino de Souza, E. C. 2013. "A arte de contar e trocar experiências: reflexões teórico-metodológicas sobre história de vida em formação", en Revista educação em questão. v. 25, n. 11 (jan./abr., 2006).

51 José Contreras Domingo, “Ter histórias para contar: aprofundar narrativamente a educação”, en Roteiro, Joaçaba, v. 41, n. 1 (jan./abr (2016), 15-40.

52 Entrevista de Helena, Pt (2016). 
os pais, com os pares, entre outras possibilidades. A experiência nos dá segurança, mesmo sabendo que cada dia é diferente do outro, que cada turma tem as suas particularidades ${ }^{53}$.

Josso revela que os contextos, nos quais transitamos as experiências de "ter e fazer" ${ }^{\prime \prime}$, enquadram-se no tipo de interações e de transações conosco, com os outros e com o ambiente natural ou com as coisas; logo, são mais localizados. Porquanto o "pensar sobre" é mais geral, obriga a colocarmo-nos em relação a outras experiências de nossa vida, impulsionando-nos a novas relações e a novos significados que nos sirvam de interpretação.

Em outra situação, as professoras narram o quanto os processos comunicacionais em sala de atividades podem promover a experiência ou, mesmo, permitir que sejamos capazes de reconhecer que a sua aquisição foi um dado significativo nas situações que enfrentamos no cotidiano da profissão. Nesse sentido, Graça narra uma situação vivenciada:

Eu lembro-me de uma situação concreta de um garoto que, chegava o dia 28 de cada mês, e dizia 'hoje faço anos', eu dizia 'não, António, tu não fazes anos hoje, tu já fizeste no mês passado'; mas para mim era um dado adquirido, porque nós tínhamos feito, conforme foi surgindo os aniversários nós tínhamos feito um histograma, era um grupo já de grandes, com os meses, com os aniversários, para mim era um dado adquirido que, pronto, ele nitidamente estava ali a fazer uma confusão...Até que um dia o rapaz chega lá e disse 'ó Graça, eu hoje faço anos, tu não vês que eu faço anos no dia 28? Se hoje é 28 então eu faço anos', e depois ali fez-se o clique, 'Ai meu Deus, eu estou mesmo a cometer um erro...', o menino só tinha a noção mesmo do dia, do 28, do dia, portanto o mês, o ano, e isso, tinha-lhe passado, e eu nem sequer me tinha apercebido ... 55

Tal reflexão de Graça foi possível pela experiência que tem na docência que a fez ter o clique. Refletir e tirar as conclusões sobre o que o menino estava a lhe dizer e suas incompreensões e posteriores reflexões geraram aprendizagem. A reflexão sobre a vivência é chave de uma aprendizagem pedagógica consequente. Ter experiência, fazer experiência, pensar sobre a experiência ${ }^{56}$ permite a resignificação pela via da reflexão sobre a situação vivida, tornando o conhecimento tácito consciente e, logo, sendo promotora de conhecimento. Este aspecto é frequente no pensamento das professoras quando falam em experiência a partir da reflexão, em torno de ocorrências quotidianas que conflituam com conhecimentos prévios ou memórias.

Assim como Graça, Ádria também narra um episódio em sua prática no qual a experiência, assim adquirida, teve um peso fulcral para o desfecho positivo:

53 Entrevista Ádria, Br. (2016).

54 Marie-Christine Josso, Experiências de Vida e Formação.Tradução José Cláudio e Júlia Ferreira. (São Paulo Cortez, 2014).

55 Entrevista Graça, (2016).

56 Marie-Christine Josso, Experiências de Vida e Formação.Tradução José Cláudio e Júlia Ferreira. (São Paulo Cortez, 2014). 
Uma tarde estava na sala de aula quando fui interrompida por um pai, muito nervoso, dizendo: - Professora, quero saber se meu filho vem à escola para aprender ou para apanhar? Ele se referia a uma briga entre seu filho e outra criança acontecida no dia anterior após o horário das aulas. Percebi que precisava dominar aquela situação de muita tensão. O pai ameaçava entrar na sala para bater na criança que havia brigado com seu filho. Imediatamente chamei a inspetora de alunos e pedi que ficasse com a turma. Fechei a porta da sala e fiquei encostada nela, de modo a dificultar a sua entrada. E falei: O senhor tem toda razão. Como o desentendimento aconteceu depois da aula e foi levado ao conhecimento da coordenação, sugiro irmos até a sala da coordenadora para discutirmos o acontecido. Ele foi surpreendido com a minha atitude e foi se acalmando. Fomos até a sala da coordenadora, conversamos sobre o episódio que acabou sendo esclarecido. Se eu não fosse uma professora experiente talvez esta situação dilemática não teria sido resolvida e o desfecho poderia ter sido desastroso ${ }^{57}$.

Ádria narra a situação e ela própria reflete e conclui que tal desfecho se deu devido a sua experiência enquanto processo de reconstrução identitária ou de autocompreensão, como o denomina Kelchtermans ${ }^{58}$. Segundo Josso, "falar das próprias experiências formadoras é, pois, de certa maneira, contar de si mesmo, a própria história, as suas qualidades pessoais e socioculturais, o valor que se atribui ao que é 'vivido', na continuidade temporal do nosso ser psicossomático" 59 .

Nesse sentido, Ádria, uma profesora com mais de trinta anos de magistério, afirma que a experiência possibilita, ao professor, na situação de conflito, “buscar na memória um episódio semelhante vivido e refletir sobre como foi solucionado ou não. Até mesmo uma experiência desastrosa, ou não resolvida, pode ajudar a trazer elementos para a compreensão do dilema a ser enfrentado"60. A professora Graça também sinaliza, em um episódio de sua prática, o quanto "ter experiência" e poder "contar com a experiência" foi importante. Ela observou duas crianças comentando sobre o fato de a mãe de um deles estar esperando bebê:

A tua mãe vai ter um bebé? como é que a tua mãe vai ter um bebé?', 'olha, tem o bebé na barriga', dizia-lhe o do lado, e eu deixei a conversa correr, e depois o do lado diz-lhe 'olha, então a tua mãe de certeza que comeu um bebé ao pequeno-almoço, para ele ir ali para a barriga', mas assim, com um ar muito sério, e quando ele diz isso, os outros começaram todos a rir, começaram a rir, 'ai, o fulaninho disse que ele comeu um bebé ao pequeno-almoço', e pronto, e eu aí já tinha mesmo que, não podia

57 Entrevista Ádria, Br. (2016).

58 G. Kelchtermans, G. 2009. “O comprometimento profissional para além do contrato: Autocompreensão, vulnerabilidade e reflexão dos professores", en Aprendizagens e desenvolvimento profissional de professores: contextos e perspectivas, organizado por M.A. Flores e A.M.V. Simão. (Mangualde: Pedagogo, 2009), 61-98.

G. Kelchtermans, G 2016. "O comprometimento profissional para além do contrato: autocompreensão, vulnerabilidade e reflexão dos professores", en Methodological Advances in Research on Emotion and Education, editado por M. Zembylas and P.A. Schutz. (Switzerland: Springer International Publishing, 2016), 31-42.

59 Marie-Christine Josso, Experiências de Vida e Formação.Tradução José Cláudio e Júlia Ferreira. (São Paulo Cortez, 2014 ), 48.

60 Entrevista Ádria, Br. (2016). 
deixar a situação, pronto, então tivemos que agarrar a situação e então começámos a falar sobre o assunto, sobre o que é que eles achavam, como é que então o bebé teria ido para a barriga da mãe, [...].Então lá exploramos, eu deixei que eles falassem, as concepções que cada um tinha, deixei que partilhassem todos, o que é que um achava, o que é que o outro achava, e depois, e depois eu disse-lhes, disse assim: 'pronto, agora vamos fazer assim... Agora vocês vão para casa e vão conversar com os vossos pais e amanhã voltamos à conversa, amanhã voltamos a falar no assunto, mas agora ficamos aqui.[... $]^{61}$

Então, ao nos depararmos com o tratamento dado pelas professoras aos fatos apresentados, observamos o quão importante é o tempo de magistério e o fato de saber usar conhecimentos prévios e a experiência neles conquistada para a resolução de problemas. Assim sendo, é possível afirmar que a situação de professoras bem-sucedidas se deva não somente à formação inicial e continuada, mas, principalmente, à forma como lidam com o resultado de suas experiências, tornando-as aprendizagens, isto é, construindo saberes profissionais dentro da profissão, transformando-se em profissional, e também a sua pessoa, num caminhar a partir de si.

Sobre isso, Ádria relatou que:

Acho pertinente dizer que a experiência profissional caminha junto com a experiência pessoal. Carrego marcas de experiências pessoais que acabam refletidas na minha prática docente. Minhas experiências pessoais de leitura na infância estão presentes na minha sala de aula, no trabalho de formação de crianças leitoras. A minha paixão pela arte também transita entre os pequenos que vivenciam ricas experiências artísticas. As experiências de vida compõem a experiência docente. A minha experiência profissional tem sido um elemento de grande valor na minha atuação docente ${ }^{62}$.

Ou seja, podemos falar de contaminação de experiências, no sentido em que experiências vivenciadas numas situações influenciem (contaminem) experiências noutras situações. Assim, assumir papéis sociais de responsabilidade com crianças (por ex.: ser pai ou mãe) leva à ressignificação das funções educativas, da identificação com perfis de atuação, a partir de questões que cada um coloca a si próprio, por exemplo: que tipo de professor sou e quero ser - autoritário, permissivo, responsabilizante? ${ }^{63}$

Ou seja, podemos falar de contaminação de experiências, no sentido em que experiências vivenciadas numas situações influenciem (contaminem) experiências noutras situações. Assim, assumir papéis sociais de responsabilidade com crianças (por ex.: ser pai ou mãe) leva à ressignificação das funções educativas, da identificação com perfis de atuação, a partir de questões que cada um coloca

61 Entrevista Graça, Pt, (2016).

62 Entrevista Ádria, Br. (2016).

63 Teresa Sarmento, "Histórias de vida de educadoras de infância". Lisboa: Col. Ciências da Educação, IIE, n47 (2002) e Teresa Sarmento, "Contextos de vida e aprendizagem da profissão", en Júlia Oliveira-Formosinho, (Porto: Porto Editora, 2009), 303-327. 
a si próprio, por exemplo: que tipo de professor sou e quero ser - autoritário, permissivo, responsabilizante? ${ }^{64}$

\section{CONCLUSION}

Ainda sem concluir: o que continuam fazendo as professoras com o que fazem com elas?

O texto aqui produzido aborda alguns aspectos em que a experiência é relevante para a docência; entre eles, a dos episódios passados em sala de aula, na relação direta com as crianças que, após serem refletidos, passam a ser recuperados em novas situações, bem como aquelas que vêm da trajetória familiar e que afetam também a nossa prática docente. Há ainda outras experiências importantes que constituem, identitariamente, o professor, começando pela própria experiência de aluno, entre elas, as vividas entre os pares e amigos as quais também incorporam o ideário do professor, entre outras tantas que acontecem em situações de improviso, esporádicas e inesperadas, em outros tempos e outros lugares e com outros componentes formativos. $\mathrm{O}$ texto e a pesquisa não concluídas ainda têm muito a relatar, pois o corpus de pesquisa analisado evidencia que tornar-se professora referência, acontece após a formação inicial, a partir das relações estabelecidas com os alunos, pais, colegas, gestão, formação continuada e, nesse caso, o clima da escola é propulsor de experiências significativas e tem relevância nos estudos dessa natureza.

Ao tratar das experiências formadoras, Josso sugere que, para compreender a construção da experiência, é necessário partir de três modalidades de elaboração:

1. "ter experiências": aqui se enquadram as vivências de acontecimentos que ocorreram durante a vida e se tornaram significativos, mas sem tê-los provocado;

2. "fazer experiência": nesta esfera, estão as vivências de situações e acontecimentos que nós próprios provocamos; quer dizer, são as situações que criamos, de propósito, para fazer experiências;3. "pensar sobre as experiências": estão, nesta categoria, aquelas experiências que tivemos sem procurá-las quanto aquelas que nós mesmos criamos $^{65}$

As professoras acentuam que as experiências que constituem a docência nem sempre são aquelas vivenciadas no tempo de magistério. Há uma gama de experiências da vida pessoal que emerge no cotidiano da prática, são nela introduzidas a partir das reflexões que se fizeram quanto à adequação das mesmas às situações de ensino. São experiências de (re)significação da formação por participarem de novos momentos formativos ${ }^{66}$.

\footnotetext{
64 Ibid

65 Marie-Christine Josso, Experiências de Vida e Formação.Tradução José Cláudio e Júlia Ferreira. (São Paulo Cortez, 2014),48

66 Teresa Sarmento, "Histórias de vida de educadoras de infância". Lisboa: Col. Ciências da Educação, IIE, n47 (2002).
} 
Deste estudo, para além da nossa reflexão sobre a experiência enquanto elemento (re)construtivo das identidades docentes, queremos reforçar a pertinência de dois outros elementos: i) a relevância de nos mantermos em constante contato com professores da educação básica, de forma a garantirmos a nossa atualização permanente sobre os (novos) modos de ser professor, as condições de (re)significar as suas identidades, as oportunidades de conhecer formas diversas de construir saberes profissionais. Reforçamos, por isso, que os métodos biográficos são, para nós, a metodologia credível de fazer ciência sobre a identidade dos professores; ii) a importância que está a se constituir para nós, investigadoras portuguesas e brasileiras, a realização de trabalho cooperativo, no que isso comporta de reconceptualização teórica, de aprofundamentos partilhados e de aposta em alargar fronteiras de conhecimento. Podemos, assim, dizer que temos altas expectativas de que a experiência que estamos a vivenciar se constitua em novo conhecimento profissional.

\section{REFERÊNCIAS}

Anastasiou, L. G. C. “Trilhas para análise da formação docente, inicial e continuada”, En Desafios e trajetórias para o desenvolvimento profissional docente, organizado por Pryjma, M. Curitiba: Ed. UTFR, 2013, 11-18.

Bertaux, D. Les récits de vie. Paris: Nathan, 1997.

Cohen, L. e Manion, L. “Métodos de Investigación Educativa”. Madrid: Muralla, 1990.

Connelly, M. e Clandinin, J. Stories of experience and Narrative Inquiry. Educational Researcher, vol. 19, n 5 (Jun-Jul 1990): 2-14.

Contreras, J. C. “Ter histórias para contar: aprofundar narrativamente a educação”. Roteiro, Joaçaba, v. 41, n. 1 jan./abr. (2016): 15-40.

Contreras, J. C. "La experiencia y la investigación educativa”. En Investigar la experiencia educativa , compilado por Contreras; J. e Pérez De Lara, N. F. (Madrid: Morata, 2010), 21-86.

Delory-Momberger, C. "Abordagem metodológica na pesquisa biográfica". Revista Brasileira de Educação, v. 17, n. 51, set./dez (2012): 523-740

Dominicé, Pierre. "O processo de formação e alguns dos seus componentes relacionais". En $O$ método (auto)biográfico e a formação, organizado por Antonio Nóvoa e Matthias Finger. Natal, RN: EDUFRN; São Paulo: Paulus, 2010.

Galvão, C. "Narrativas em educação". Ciência \& Educação. v. 11, n. 2 (2005): 327-345.http://www. scielo.br/scielo.php?pid=S1516-3132005000200013\&script=sci_arttext (15/03/2013).

Ghedin, E., Almeida; M. e I. Leite, Y. U. F. Formação de professores. Caminhos e descaminhos da prática. Brasília: Líber Livro, 2008.

Goodson, I. F. Developing narrative theory. London: Routledge, 2013.

Josso, M. C.. Experiências de Vida e Formação.Tradução José Cláudio e Júlia Ferreira. São Paulo Cortez, 2004.

Kelchtermans, G. “O comprometimento profissional para além do contrato: Autocompreensão, vulnerabilidade e reflexão dos professores". En Aprendizagens e desenvolvimento profissional de professores: contextos e perspectivas, orgs. Flores, M.A. e A.M.V. Simão. Mangualde: Pedagogo, 2009, 61-98.

Kelchtermans, G. "O comprometimento profissional para além do contrato: autocompreensão, vulnerabilidade e reflexão dos professores". En Methodological Advances in Research on Emotion and Education, eds M. Zembylas and P.A. Schutz Switzerland: Springer International Publishing, 2016.

Leal da Costa, C. Viver Construindo Mudanças - a vez e a voz dos professores. Contributo para os estudos da aprendizagem e desenvolvimento dos professores. Tese de Doutoramento en Universidade de 
Évora, 2015.

Leal da Costa, C.; Biscaia, C. “Um olhar em torno de possibilidades de conhecer a diferença de forma diferente", En Notas de uma investigação com narrativas de vida, coords L. Del Río Bermudez e P. Àlvarez TEVA. FECIES. Granada: Asociación Española de Psicología Conductal, 2012, 1359-1365.

Marcelo, C. "A identidade docente: constantes e desafios". Revista Brasileira de Pesquisa sobre Formação Docente. Belo Horizonte, v.01, n. 01 ago./dez, (2009):109-131.

Martins, R. M. Aprendendo a ensinar: as narrativas autobiográficas no processo de vir a ser professora. Tese de Doutoramento em Educação en Universidade Federal de São Carlos, 2015.

Martins, R. M. Nada é mais formativo do que a própria formação acadêmica associada às experiências e à prática: narrativas autobiográficas de uma professora experiente, Anais do VIII Congresso Internacional de Pesquisa (auto)biográfica-VIII CIPA. São Paulo:UNICID, 2018.

Mizukami, M. G. N. et al. Escola e aprendizagem da docência: processos de investigação e formação. São Carlos: EdUFSCar, 2003.

Monteiro, M. I. Histórias de Vida: saberes e práticas de alfabetizadoras bem-sucedidas.Tese de Doutorado em Educação en Faculdade de Educação da Universidade de São Paulo, 2006.

Monteiro, M. I. “Histórias de vida de alfabetizadoras bem-sucedidas no períood de 1950 a 1980". En Desenvolvimento profissional da docência: teorias e práticas, orgs. Maria Graça Mizukami e Aline Maria de Medeiros Rodrigues Reali. São Carlos: EduFSCar, 2012, 105-128.

Nóvoa, A.“O passado e o presente dos professores”. En Profissão Professor, org. Nóvoa, A. Porto: Porto Editora, 1991, 9-33.

Nóvoa, A. Os professores e a sua formação. Lisboa: Ed. Dom Quixote, 1997.

Nóvoa, A. “Os professores e as histórias da sua vida". En Vida de professores, Org Nóvoa, A. 2. ed. Portugal: Porto, 2000.

Nóvoa, A. "A formação tem que passar por aqui: as histórias de vida no Projeto Prosalus". En O método (auto) biográfico e a formação, Orgs Nóvoa, António e Finger, Matthias. Natal: EDUFRN; São Paulo: Paulus, 2010.

Nóvoa, A. Finger, M. (orgs.). O método (auto) biográfico e a formação. Natal: EDUFRN; São Paulo: Paulus, 2010.

Nóvoa, Antonio. O regresso dos professores. Pinhais: Editora Melo, 2011.

Passeggi, M. C. “Dimensões epistemológicas e metodológicas da pesquisa (auto)biográfica”. En Congresso Internacional de Pesquisa (Auto)biográfica. Porto Alegre. Mesa Redonda. Porto Alegre: PUCRS, 18 out. 2012.

Passeggi, M. C. “Nada para a criança, sem a criança: o reconhecimento de sua palavra para a pesquisa (auto) biográfica". En Infância, aprendizagem e exercício da escrita, MIGNOT, A. C.; Sampaio, C. S.; Araújo, M.; Passeggi, M. Curitiba: Crv, 2014.

Sampaio, C. S.; Araújo, M.; Passeggi, M. Curitiba: Crv "Narrativas da experiência na pesquisa-formação: do sujeito epistêmico ao sujeito biográfico". Roteiro, Joaçaba, v. 41, n. 1 (jan./abr 2016): 15-40.

Passeggi, M.C. Souza e Vicentini, P.P. 2011. “Entre a Vida e a Formação: Pesquisa (auto)Biográfica, docência e Profissionalização". Educação em Revista, 27 (1), (2011): 369-386.

Pineau, G. "As histórias de vida em formação: gênese de uma corrente de pesquisa-ação-

formação existencial", Educ. Pesquisa [online], vol.32, n.2 (2006): 329-243

Pineau, G. "A tríplice aventura (auto)biográfica: a expressão, a socialização e a

Formação". En Dimensões epistemológicas e metodológicas da pesquisa (auto)biográfica, orgs Passeggi, M. C. e Abrahão, M. H. B. Tomo I. Natal: EDUFRN; Porto Alegre: EDIPUCRS; Salvador: EDUNEB, 2012, 139-158.

Poirier, J., Clapier-Valladon, S. e Raybant, P. Histórias de Vida - Teoria e Prática. Oeiras: Celta Editora, 1995.

Reali, A.M., Tancredi, R.M. e Mizukami, M.G. “Programa de mentoria online: espaço para o desenvolvimento profissional de professoras iniciantes e experientes". Educação e Pesquisa, v.34, n.1 (2008): 77-95.

Reali, A.M. e Reyes, C. R. Reflexões sobre o fazer docente. São Carlos: EdUFSCar, 2009.

Rocha, S. A. Formação de licenciandos e constituição da identidade docente. Relatório de Pós-Doutorado 
En Programa de Pós-Graduação em Educação e Psicologia da PUC. São Paulo, 2011.

Santos, Maricéa do Sacramento. Reflexões e prática de uma professora bem-sucedida. Tese de Mestrado em Educação en Universidade Federal de São João Del-Rei, 2010.

Sarmento, T. Histórias de vida de educadoras de infância. Lisboa: Col. Ciências da Educação, IIE, nº47, 2002.

Sarmento, T. "De estudante a educadora de infância: expectativas e ansiedades no processo de inserção profissional". En Revista Galego-Portuguesa de Psicoloxia e Educacion, nº8 (vol 11), ano 7 (2003): 1242-1253.

Sarmento, T. "Contextos de vida e aprendizagem da profissão". En Formação de professores, Formosinho, J. Porto: Porto Editora, 2009.

Formosinho, J. Porto Aprender a profissão em diferentes espaços da vida. Revista de Educação, PUC Campinas, 18(3), (2013): 237-248.

Souza, E. C. "A arte de contar e trocar experiências: reflexões teórico-metodológicas sobre história de vida em formação". En: Revista educação em questão. Natal, RN: EDUFRN, v. 25, n. 11, (jan./ abr.,2006): 22-39. http://www.revistaeduquestao.educ.ufrn.br/pdfs/v25n11.pdf. (06/05/2013)

Vicentini, P. P., Souza, E. C. e Passeggi, M. C. (Orgs). Pesquisa (auto)biográfica. Questões de ensino e formação. Curitiba: CRV, 2013.

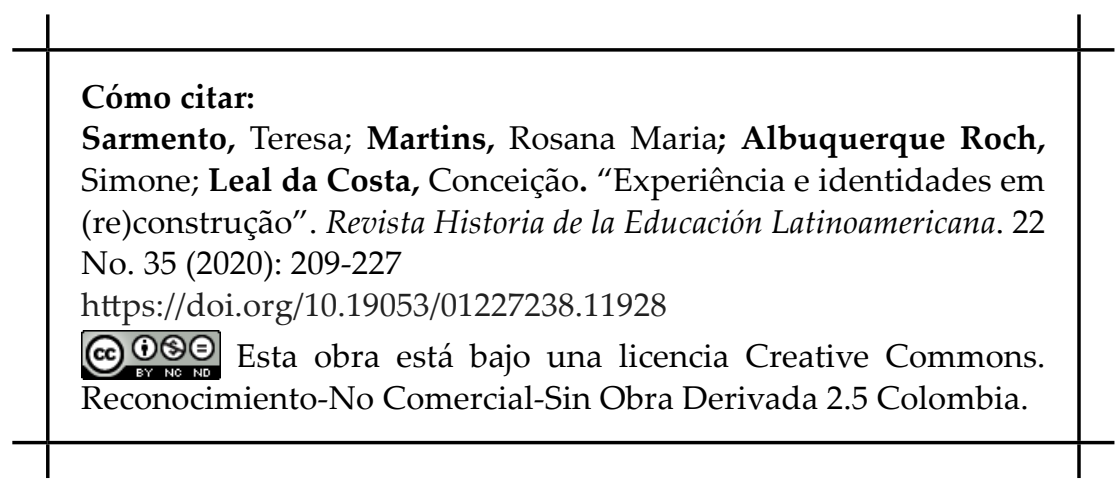


